\section{PERIPARTUM CARDIOMYOPATHY AND ANAESTHESIA}

Dear Editor,

7 his is with reference to the case report "Peripartum Cardiomyopathy and anaesthesia (MJAFI 1994; 50 : 221-2). Cortain features about the case require reconsideration as explained below.

1. Common ECG changes of dilated cardiomyoparthy are non-specific ST-T changes and anterior $Q$ waves. Changes of LVH are rare. In this case, a possibility of pre-existing hypertensive heart disease is likely, which could have aggravated the cardiomyopathy. Alternatively since echocardiography did not dem- onstrate LVH, the ECG changes could be non-specific rather than of ventricular hypertrophy.

2. The $\mathrm{X}$-ray changes should read as pulmonary venous hypertension/pulmonary vascular redistribution.

3. As the patient was maintaining normal sinus rhythm the role of digitalis is controversial. Diuretics and vasodilators would alone have sufficed and low dose aspirin could have been added as it is indicated cardiomyopathy.

Maj RG PODUVAL

Graded Specialist (Medicine)

Military Hospital Kamptee

\section{Author's Reply}

1. Non-specific ST \& T changes may be common ECG finding in dilated cardiomyopathies. However in this particular case, the patient showed clear clinical features of LVF and ECG findings were typical of LVH with strain pattern i.e. depressed ST segment and inverted $T$ waves. This patient did not give any history of hypertensive heart disease prior to present pregnancy. Her previous pregnancies and deliveries were uncomplicated. However, I agree that echocardiography findings were suggestive of dilated cardiomyopathy.

2. I also agree with the writer that chest radiograph findings were those of pulmonary venous hypertension.
3. As the patient showed signs of congestive heart failure with marked tachycardia and poor myocardial contractility, she was digitalised to improve cardiac output, to reduce mismatch and to improve oxygen delivery to tissues. As the plan was to take up the patient for LSCS at the earliest to save the mother as well as the baby, initial trial with vasodilators and diuretics would have perhaps delayed this life saving operation with unfavourable outcome.

\section{Col PM VELANKAR}

Reader. Dept of Anaesthesiology. Armed Forces Modical College, Pune.

\section{TUMOUR ASSOCIATED BLOOD EOSINOPHILIA}

Dear Editor,

W e wish to share with our readers a study pertaining to tumour associated eosinophilia (TABE). A total of 596 patients with biopsy confirmed malignancy were screened for eosinophilia. A differential loukocyte count in excess of $10 \%$ was taken as significant [1]. The pationts having eosinophilia due to known causes as parasitic infections, allergies, collagen vascular diseases, drug reactions etc were excluded from this study. A control group from a similar cross section of population was also screened for eosinophilia. It was observed that the inci- dence of eosinophilia in patients suffering from malignancy was $12.6 \%$. The overall incidence of eosinophilia in the control group was $6 \%$. The highest incidence of eosinophilia was in Hodgkins disease, followed by Non Hodgkins lymphoma and carcinoma cervix. Patients with disseminated disease often showed eosinophilia.

The association between blood eosinophilia and malignant tumours was described by Isaacson in 1946. It is an easily recognisable condition and is often associated with poor prognosis $[1,2]$. It has been reported in various types of malignancies. A high incidence of TABE in Hodgkins disease is recorded in literature [2]. The cause for eosinophilia is not yet clearly defined. It has been linked with necrosis in the primary tumour or its motastases [3], immune complex formation with 
subsequent histamine release [2] etc. It is presently considered that TABE is due to production of granulocytemacrophage stimulating factor by the tumour, but this has not been conclusively proved [4]. The role of eosinophils is still uncertain and needs further research both morphologically and immunologically at the affected tumour site.

Maj HARSH KUMAR, Surg Cdr P SIVADAS, Lt Col R RANGARAO, Col JR BHARDWAJ Dept of Pathology, AFMC, Pune.

\section{REFERENCES}

1. Isaacson NH, Rappaport P. Eosinophilia in malignant tumours : Its significance. Ann Intern Med 1946; 25 : 893-902.

2. Lowe D, Jorizzo J, Hutt MSR. Tumour associated eosinophilia : a reviow. J Clin Pathol 1981; 34 : 1343-8.

3. Fahey RJ. Unusual leukocyte responses in the primary carcinoma of the lung. Cancer 1951; 4 : 930-5.

4. Sawer CL, Golde DW, Quan S, Nimer SD. Production of Granulocyte-Macrophage-Colony estimulating factor in two patients with lung cancer. Leukocyte and eosinophilia. Cancer 1992; 69 : 1342-6. 